\title{
DEL CONFLICTO A LA CONCILIACIÓN Y VICEVERSA: ALGUNAS NOTAS ACERCA DE LA DIALÉCTICA DE RICAUR
}

\author{
Gonçalo Marcelo* \\ doi:10.11144/Javeriana.uph31-63.ccdr
}

\begin{abstract}
RESUMEN
Este artículo analiza el uso metodológico de la dialéctica en la filosofía de Paul Ricœur, al sostener que está fundamentalmente animada por la interacción entre el conflicto y la conciliación. Esbozaremos un modelo interpretativo alternativo con el fin de aproximarnos a una comprensión más cabal del original aporte de Ricœur a la filosofía. Para ello, será propuesta una reconstrucción racional de su método, desde la que evaluaremos las nociones de "kantismo pos-hegeliano", conflicto, mediación, conciliación y dialéctica, y enfatizaremos la importancia del lector comprometido. Se argumentará que una de las contribuciones decisivas de Ricœur a la filosofía consiste en mostrar que se puede ser original siendo riguroso, así como el que la perspectiva ampliada que se posibilita por el penser ensemble consigue explicar varios fenómenos, lo cual permite evitar el reduccionismo y embarcarse, así, hacia una búsqueda de sentido que se actualiza en un proceso de reinterpretación constante.
\end{abstract}

Palabras clave: Ricœur; Kant; dialéctica; conflicto; conciliación

\footnotetext{
*Universidade Nova de Lisboa, Lisboa, Portugal.

Recibido: 05.05.14 ACEPTADO: 16.06.14

DisPONIBLE EN LÍNEA: 02.12.14

Una versión más corta de este artículo fue presentada en la Society for Ricœur Studies Fall Conference, que tuvo lugar en George Mason University en Arlington, Virginia, el 2009; una versión francesa, ligeramente modificada, en la Université Catholique de Louvain en Diciembre del 2009, en el Europe-Groupe de investigadores de filosofía práctica.
}

La presente traducción al castellano, realizada por Luz María Ascárate Coronel, Pontificia Universidad Católica del Perú (Lima-Perú), procede del artículo en inglés: Marcelo, G. (2010). From Conflict to Conciliation and Back Again: Some Notes on Ricœur's Dialectic. Revista Filosófica de Coimbra, 19(38), pp. 341-366.

Para citar este artículo: Marcelo, G. (2014). Del conflicto a la conciliación y viceversa: Algunas notas acerca de la dialéctica de Paul Ricœur. Universitas Philosophica, 31(63), pp. 181-211, ISSN 0120-5323, ISSN en línea 2346-2426, doi: 10.11144/Javeriana.uph31-63. ccdr 


\title{
FROM CONFLICT TO CONCILIATION AND BACK AGAIN: SOME NOTES ON RICCEUR'S DIALECTIC
}

\author{
GonÇALO MARCELO
}

\begin{abstract}
This paper analyzes the methodological use of dialectic in the philosophy of Paul Ricœur, arguing that at its core this philosophy is moved by the dynamics stemming from the interaction between conflict and conciliation. In sketching an alternative model to better understand Ricœur's original approach to philosophy, my rational reconstruction of his method assesses his "post-Hegelian Kantism", the procedures of conflict, mediation, conciliation and dialectic and the importance of the engaged reader. I will contend that one of Ricœur's lasting contributions to philosophy is to show how one can be original while being thorough and that the enlarged perspective built by his thinking together successfully explains phenomena by avoiding reductionism and striving for the quest of new meaning through a process of perpetual reinterpretation.
\end{abstract}

Key words: Ricœur; Kant; dialectic; conflict; conciliation 
¿CUÁl es LA DIFERENCIA, SI ES QUE HAY TAL, entre un académico y un pensador auténtico? ¿Es realmente posible arribar originariamente a algún pensamiento y llegar a conclusiones coherentes a la vez que se ignoran por completo los esfuerzos que han hecho otros en los mismos temas, los pensamientos que han cobrado vida - que han llegado a ser realmente actuales - a partir de obras valiosas que se han convertido en parte de aquello a lo que llamamos tradición? Aparentemente, sí; Wittgenstein, por ejemplo, enfatiza el nunca haber leído a Kant, a pesar de las obvias similitudes entre el Tractactus del primero y la filosofía trascendental del último. En la tradición continental europea, los filósofos han dado especial atención a la historia de la filosofía; su particular cuidado usualmente contrasta con la forma en la que los filósofos analíticos prestan atención a la validez de los argumentos en sí mismos, dejando en segundo plano el componente histórico.

Por tanto, en este sentido, uno puede, al menos desde la filosofía de estilo continental, establecer una distinción entre 1) un académico, que está particularmente familiarizado con la tradición y es ampliamente competente en cuestiones filológicas, y 2) aquel que desarrolla una nueva, poderosa e inteligente filosofía, dejando de lado casi por completo la tradición. La pregunta, entonces, que tenemos que hacernos es si estas son alternativas excluyentes (de tipo $o \ldots o$ ). Y la respuesta debe ser: "obviamente, no", como bien reconocería quien ha sido iniciado en el tipo específico de racionalidad representado por la hermenéutica. Sería, pues, del todo ingenuo considerar que una tal originalidad es espontánea, efectuada ab nihilo. Antes bien, no se debe subestimar el poder de la apropiación hermenéutica en la producción del pensamiento propio; Selbstdenken y la hermenéutica no son incompatibles. En lo que sigue se argumentará, así, que la filosofía de Paul Ricœur es un buen ejemplo de dicha capacidad.

Debemos comenzar por afirmar que lo que aquí buscamos proponer un modelo interpretativo para entender y describir aquello que está en juego en la filosofía de Paul Ricœur, al ser tomada en su totalidad. Con mostrar ello, se espera dar luces acerca de la concepción de la filosofía del propio Ricœur -y lo que puede enseñarnos sobre ello-. Así también, diseñar este modelo nos ayudará a emprender una cierta reconstrucción racional de la filosofía ricœuriana de acuerdo con nuestros propios estándares. Esperamos que esto no suponga traicionar a Ricœur mismo sino, más bien, creemos que ha de ser visto como aquel proceso necesario mediante el cual el lector de toda obra filosófica necesariamente intenta, de algún modo, presentar su propia reformulación. En cierto sentido, cada lectura es personal. Paul Ricœur, 
lector voraz y académico eminente tuvo, del mismo modo, una relación muy personal con sus lecturas. Consecuentemente, aunque el propósito de este escrito no es primordialmente explicar la naturaleza de un pensamiento original, uno de sus objetivos será mostrar cómo es posible ser original, y a la vez riguroso, usando el método filosófico de Paul Ricœur. Se han empleado muchos modelos para describir su filosofía. Uno de los más populares es el dialógico: Ricœur sería el filósofo del diálogo, incluso "le philosophe de tous les dialogues". Esto puede ser cierto debido a su habilidad para escuchar a sus contemporáneos e interactuar con ellos de modos significativos. No obstante, este modelo tiene quizá la debilidad de interpretar el pensamiento ricœuriano de forma muy benévola. Con ello, se corre el riesgo de olvidar las tensiones presentes en el corazón de su filosofía. Por otro lado, un modelo distinto pone énfasis en la noción de conflicto qua conflicto, argumentando que no hay tal cosa como un proceso de Aufhebung entre todas estas contradicciones y que debemos respetar la existencia de una pluralidad de conflictos como tal.

Esto plantea la difícil pregunta acerca de la tarea propia de la razón en la filosofía: ¿Qué rol, si hay tal, tienen hoy en día las categorías de totalidad y unidad en nuestra filosofía? Es decir, después del acaecimiento del movimiento posmoderno y, especialmente, luego de que Ricœur se apropiara cuidadosamente de la filosofía levinasiana, ¿puede él -o cualquiera de nosotros, incluso- conscientemente, intentar formar un sistema filosófico unitario sin la ligera sospecha de ser parte de un proceso de dominación, que suprime la alteridad con el irrefrenable curso de la razón? Con este estado de cosas en mente, es necesario remarcar que cualquier búsqueda de unidad en la filosofía ricœuriana es hipotética; muchos intérpretes han tratado de encontrar una, recurriendo a conceptos tales como acción, voluntad, imaginación, hermenéutica. Si bien ninguna de estas aproximaciones ha sido errónea, ninguna es enteramente correcta. Sostendremos aquí, más bien, que no hay una unidad real en la filosofía de Ricœur, sino muchas posibles unidades configuradas por diferentes atracciones hacia posibles unidades, que pueden ser hechas y rehechas a través del proceso de interpretación.

Es cierto que el académico ricœuriano, incluso nuestro filósofo mismo, ha tenido siempre en cuenta las dicotomías que impregnan su actitud hermenéutica. Esto puede ser considerado de formas muy diversas, aunque similares, si señalamos aquella de la crítica y la convicción o, como Andrew Wiercinski (2003) señala, la de la simpatía y la sospecha. Proponemos 
aquí que podemos encontrar inclusive otra de estas reveladoras dicotomías que atraviesan el trabajo de Ricœur: la del conflicto y la conciliación. De este modo, este ensayo argumentará que aquello es justamente lo que constituye el corazón de su dialéctica filosófica, la que está simultáneamente inspirada en Hegel pero con el suficiente cuidado como para no seguirlo hasta el final de la completa mediación. Hegel es, como Husserl y Kant, una de las principales figuras que aparecen a lo largo del entero corpus de los escritos ricœurianos pero a quienes Ricœur nunca les prometió lealtad. En algunos pasajes concuerda con Hegel; en otros usa la filosofía hegeliana cuidadosamente; y podemos encontrar todavía otros en los que desacuerda completamente con Hegel. Esto ocurre, en primer lugar, porque el filósofo francés procede, como sostendremos aquí, analizando problemas filosóficos en tanto tales. Nunca quiere realmente rendir lealtad a un único filósofo o tendencia, incluso si reconoce su deuda hacia otros. En realidad, al reconocer la amplitud y la diversidad de su filosofía, Ricœur trata, desde 1980 en adelante, de comprender la coherencia de su trabajo y las tradiciones con las que está en deuda. Identifica, así, tres principales movimientos filosóficos que le han garantizado una formación sólida, y que han formado su horizonte:

Me gustaría caracterizar la tradición filosófica a la que pertenezco mediante tres aspectos: está en la línea de una filosofía reflexiva; se incluye en el movimiento de la fenomenología husserliana; quiere ser una variante hermenéutica de esta fenomenología ${ }^{1}$.

No obstante, este reconocimiento no impide que Ricœur reflexione sobre los problemas filosóficos en sí mismos. Esto es evidente por la manera en la que fue movido por los problemas específicos que encontramos en cada libro: "Además yo insisto bastante en la idea de que la filosofía se ocupa de problemas determinados, a los bien delimitados aprietos del pensamiento"2.

Esto significa que casi nunca se ocupa de cuestiones del todo comprehensivas (del tipo ¿qué es la metafísica?), y prefiere, más bien, tratar

\footnotetext{
${ }^{1}$ Traducción libre de "J'aimerais caractériser la tradition philosophique dont je me réclame par trois trais : elle est dans la ligne d'une philosophie réflexive; elle demeure dans la mouvance de la phénoménologie husserlienne; elle veut être une variante herméneutique de cette phénoménologie" (Ricœur, 1986, p. 25). En adelante, todas las traducciones del francés son de la traductora del artículo (N. T.).

2 "Je tiens d'ailleurs beaucoup à cette idée que la philosophe s'adresse à des problèmes déterminés, à des embarras de pensée bien cernés" (Ricœur, 1995a, p. 125).
} 
con problemas específicos -metáfora, narrativa, reconocimiento, entre otros-. Al hacer ello, piensa desde la tradición con el fin de ser capaz de ir más allá de la tradición -lo cual es un modo específico de dialéctica (entre la tradición y la innovación), ambos bien expresados en La metáfora viva y en Tiempo y narración-. Esto es más fácil de exponer a modo de un necesario procedimiento metodológico que, por supuesto, efectuarlo. Lo que está en juego aquí es la correcta articulación entre el procedimiento de patentar las "cosas en sí mismas" en tanto estamos confrontados a ellas y el "elemento histórico", esto es, la larga lista de aproximaciones que otros filósofos usan al tratar de entender estos mismos fenómenos y que constituyen, por decirlo de algún modo, la "historia" de ese problema. Cuando tenazmente se intenta pensar del todo solo -l'originalité à tout prix- se corre el riesgo de llegar a ser significativamente limitado por los puntos ciegos que se producen con modos de pensar viciosos y reificados.

Debemos también agregar, en beneficio del análisis de este problema, que un punto de vista completamente imparcial es, tanto como sabemos, imposible. No hay una mirada totalmente objetiva, así como no hay absoluta originalidad. Cada filosofía parte de una vida cotidiana y, en algún punto, eventualmente trata de regresar a eso, aunque con una perspectiva radicalmente diferente. La tradición, muy a menudo, tiene sus formas de volver a nosotros, incluso si lo ignoramos. Así también, existe lo que podríamos llamar una "tradición de la originalidad", es decir, una tradición de filósofos, escritores y artistas, que ha intentado e intenta ser creativa, opuesta a una "tradición de la tradición", que puede ser tildada, de algún modo, de ser un cierto conservadurismo filosófico.

Por otro lado, tratar de exponer una filosofía que sería nada más que un reflejo de casi todo lo que ha sido dicho y hecho antes enriquecería, en el mejor de los casos, la Enciclopedia, pero nunca respondería a los problemas filosóficos con los que debemos lidiar. Es así que siempre se debe encarar la difícil decisión de elegir el mejor camino -y estar propensos a la posibilidad de error-. Aquí, lo más conveniente sería ser capaces de usar lo histórico como inicio para eliminar el punto ciego del pensamiento propio, sin dejar de ser capaz, a la vez, de partir de ahí de algún modo, superando las aporías que pudieran evadir cualquier esfuerzo teorético en algún punto. ¿Acaso nos estamos aproximando a alcanzar tal capacidad? ¿Fue Ricœur mismo un modelo de este modo de pensar? Argumentaré, efectivamente, que este es el caso, asumiendo la forma específica de la interacción entre el conflicto y la conciliación, como el resto del artículo buscará mostrar. 
Pero hay un elemento adicional que tiene que ser tomado en cuenta. Si cada problema filosófico (excepto los radicalmente nuevos, que se hacen posibles solo en ciertos tiempos y en respuesta a ciertos eventos) tiene una historia, la cual es largamente constituida por los esfuerzos intelectuales de otros, los senderos que la filosofía de uno asume tienen una historia también, una que quizá esté llena de desviaciones, contratiempos y conversiones. Estas metamorfosis que tienen lugar en la filosofía son también una de las posibilidades del advenimiento de lo nuevo en ella. Dicha novedad puede ser capaz, a su vez, de dar paso a una reinterpretación del todo; esto es, cada nuevo giro teorético sería decisivo para entender -incluso en términos narrativos- el proceso visto en su totalidad. Entonces no es inocua, para el correcto entendimiento de toda esta problemática que encontramos en Ricœur, la permanente interpretación de viejas posiciones que fueron alguna vez suyas. Trataré de explicar este rasgo de su filosofía en lo que sigue. No obstante comenzaremos por exponer los conceptos principales.

Si se nos da la labor de escoger, de entre el desconcertante despliegue de conceptos que aparece en la filosofía de Paul Ricœur, a los que ha dado más énfasis en todos sus libros y que han resumido exitosamente sus mayores contribuciones como filósofo, la noción de conflicto sería ciertamente uno de ellos. Incluso aquellos que han puesto poca atención a sus obras han escuchado probablemente sobre El conflicto de las interpretaciones. El origen de esta idea, o al menos de su forma de tratarla, es el capítulo llamado "dialéctica" en De la interpretación, donde Ricœur opone dos distintos métodos de búsqueda de sentido: el modelo arqueológico, freudiano, y el modelo teleológico, hegeliano (en el que la verdad de cada figura es ser encontrada en la siguiente). Aquí es donde Ricœur realmente comienza a practicar la dialéctica, como la promoción de una tercera posición, siempre respetuoso de los dos polos opuestos de la antítesis, pero esperando superarlos a través del movimiento dialéctico; explicaremos a continuación este proceso.

Lo que está en juego, en esta fase madura de su filosofía (todos estos son artículos de los años sesenta), es, desde una primera aproximación, la posibilidad de un inmediato y transparente acceso a la propia conciencia -un problema que seguiríamos por casi tres décadas hasta Sí mismo como otro-. Ricœur ubica a Freud como uno de los "maestros de la sospecha" una expresión que llegaría a ser famosa- junto con Marx y Nietzsche.

El filósofo formado en la escuela de Descartes sabe que las cosas son dudosas, que no son lo que parecen; pero no duda de que la conciencia sea 
ella la que se aparece a ella misma; en ella, sentido y conciencia de sentido coinciden; luego de Marx, Nietzsche y Freud dudamos de ello. Después de la duda sobre la cosa, hemos llegado a la duda sobre la conciencia ${ }^{3}$.

De acuerdo con Ricœur, es obvio que realmente no podemos decir que estos tres filósofos tengan proyectos similares -aunque la expresión école $d u$ soupçoin es a veces usada, esta designación es bastante equívoca-. Evidentemente, Marx, Nietzsche y Freud tienen aserciones teoréticas substanciales, las cuales son radicalmente diferentes si consideramos lo que proponen. Sin embargo, si consideramos lo que rechazan, quizá podamos comenzar a descubrir una característica común. Ricœur propone lo siguiente: los tres rechazan la existencia de una conciencia omni-incluyente, de un sujeto que es, por decirlo de algún modo, dueño de sí mismo. Todos ellos plantean, más bien, una alternativa diferente: una dicotomía entre dos niveles de sentido: uno que es patente (mostrado) y otro, latente (oculto). El primer nivel de sentido, el cual es inmediato y conscientemente percibido, no es nada más que una ilusión producida por sentidos ocultos. De este modo, lo que realmente instituye es una exégesis del sentido. Así, como este no puede ser inmediatamente aprehendido, debe ser buscado; algún tipo de ciencia de la interpretación ha de ser, pues, establecida. Y aquí tenemos una de las mayores contribuciones del giro hermenéutico, tanto en la obra de Ricœur como en la filosofía. De ahora en adelante, el sentido no será captado inmediatamente y tomado en su valor prima facie; antes bien, es preciso descifrar sus expresiones: “(...) en adelante, buscar el sentido no es más deletrear la conciencia de sentido, sino descifrar las expresiones"4.

Ahora bien, podemos entender las similitudes entre estos tres proyectos. Están inmersos en un cierto tipo de desmitificación hermenéutica. Lo que es claro para Ricœur, sin embargo, es que no es ciertamente el único tipo de hermenéutica posible. Sus últimas obras desde las de 1960, 1970 y 1980 discutirán ampliamente el origen de la hermenéutica y sus múltiples formas en teología y filosofía, poniendo especial énfasis en las obras

\footnotetext{
3 “Le philosophe formé à l'école de Descartes sait que les choses sont douteuses, qu'elles ne sont pas telles qu'elles apparaissent; mais il ne doute pas que la conscience ne soit telle qu'elle s'apparaît à elle-même; en elle, sens et conscience du sens coïncident; depuis Marx, Nietzsche et Freud nous en doutons. Après le doute sur la chose, nous sommes entrés dans le doute sur la conscience" (Ricœur, 1965, p. 43).

4 “[C]hercher le sens, désormais, ce n'est plus épeler la conscience du sens mais en déchiffrer les expressions" (Ricœur, 1965, p. 44).
} 
de Schleiermacher, Dilthey, Gadamer y Heidegger -sin mencionar la ambigua relación que Ricœur mantuvo con el estructuralismo-. Ya en De la interpretación entendió que podemos oponer a esta hermenéutica de la sospecha una alternativa distinta: la hermenéutica en tanto recolección del sentido, la cual encontró en los trabajos pertenecientes a la fenomenología de la religión de autores como Mircea Eliade y G. van der Leeuw. Lo que Ricœur quiere defender es la posibilidad de fe, y también de moralidad, a pesar del ataque de Nietzsche. Quiere llegar a una fe poscrítica. Una fe $-\mathrm{y}$, podemos también agregar, la posibilidad de ética y moralidad- que ha sobrevivido a la prueba de su origen. En este temprano libro, lo opuesto a sospecha es la fe; en Sí mismo como otro, lo opuesto a sospecha será la atestación, la piedra angular de la última filosofía de Ricœur.

En términos de su propia metodología, inclusive la hermenéutica de la sospecha puede tener un opuesto. Cuando nuestro objetivo es la desmitificación, preciso es regresar y cavar profundamente dirigiéndonos al inicio de un cierto proceso. De este modo, aquello puede ser visto como un movimiento en retrospectiva y, al mismo tiempo, como algún tipo de excavación arqueológica, si nos es permitida la metáfora. En contraste con ello, Ricœur quiere probar que otro tipo de hermenéutica es posible; una hermenéutica cuyo movimiento, metodología y fin sean radicalmente distintos. La desmitificación hermenéutica procede a través de ciertos medios de reducción: usualmente lo encontramos expresado en fórmulas como "moralidad no es nada más que..." o "la razón no es sino..."; el maestro de la sospecha se encuentra, pues, aquí, para prevenirnos de ser engañados por falsos ídolos. Hace esto eliminando el sentido falso y señalando la causa real, el real (incluso si es unidimensional) sentido.

Entonces, ¿cuál es la hermenéutica alternativa que Ricœur quiere proponer? En De la interpretación, está enfocado en lo que él llama una hermenéutica amplificada. Este tipo de hermenéutica no reduce el segundo sentido al primero -más bien, procede teleológicamente- desplegando el sentido gradualmente, paso a paso. Cada nuevo paso nos da un sentido más verdadero, más amplio, que comprende lo que ha sido mostrado hasta este punto pero que continúa más allá de él. Lo que Ricœur tiene en mente, como se entiende fácilmente con miras a lo ya dicho, es la Fenomenología del espíritu de Hegel. Cada nueva figura trae la verdad a la anterior. ¿Y si el verdadero significado de un cierto fenómeno no puede ser realmente captado arqueológicamente sino teleológicamente? ¿Y si descubriéramos 
que debemos permitir el desarrollo de su curso teórico en lugar de intentar captarlo completamente? A la hermenéutica de la sospecha se opone, pues, la hermenéutica de la recolección del sentido; a la hermenéutica arqueológica, la hermenéutica teleológica. De este modo, tiene lugar el conflicto y es ahí donde adquiere su debida importancia para Ricœur. Aún así, desde el punto de vista de un observador externo, aquel que pudiera ver la completitud del desarrollo de la filosofía de Ricœur a lo largo del tiempo y el camino que devela, incluso en un sentido narrativo, nos encontramos, con la publicación de De la interpretación y El conflicto de las interpretaciones, ya in medias res. Lo que tiene que ser probado todavía es la relevancia de esta noción más allá del periodo específico de los años 60.

Un importante y extenso debate tuvo lugar para determinar lo que se había de hacer con la figura conceptual del conflicto en el contexto de la filosofía ricœuriana, siendo esta tomada en su totalidad. Si es cierto que fue solo con el giro hermenéutico de su filosofía que el filósofo francés dio a la noción de conflicto su mayor importancia, uno puede quizá decir que el choque entre fuerzas teóricas opuestas ha sido siempre, de algún u otro modo, característico de su forma de pensar: "Estoy agradecido de haber sido solicitado desde el principio por fuerzas contrarias y fidelidades opuestas" 5 .

Ya en Lo voluntario y lo involuntario, su primer proyecto filosófico autónomo, afirma que la verdadera conexión entre estas realidades fenomenológicas nos es mostrada por la reveladora fuerza del conflicto ${ }^{6}$. Más tarde, la fase hermenéutica de la producción de Ricœur nos trajo a reflexiones sobre los símbolos y su inherente sobredeterminación, la cual es explicada por el choque de diferentes interpretaciones, como hemos visto. El punto es el siguiente: los símbolos nunca son simples. Tienen, más bien, múltiples capas de significado y, en ellos, los diferentes estilos hermenéuticos luchan por imponer su propia interpretación. "Los verdaderos símbolos son semillas del avenir de toda hermenéutica"7.

\footnotetext{
5 "Je suis reconnaissant d'avoir été dès le début sollicité par des forces contraires et des fidélités opposées" (Ricœur, 1987, p. 1).

6 "De proche en proche les rapports de l'involontaire au volontaire se révèlent sous le signe du conflit" (Ricœur, 1950, p. 21).

7 “Les vrais simboles sont gros de toutes les herméneutiques" (Ricœur, 1969, p. 27).
} 
Consecuentemente, si nos es permitido caracterizar a algún tipo de pensamiento por referencia a su movimiento inherente, es decir, apelando al modo en el que las fuerzas que lo habitan interactúan entre ellas y toman una forma específica, podemos decir ciertamente que aquello que constituye el motor del pensamiento de Ricœur se hace posible por la dinámica de la antítesis. Así mismo, dado que la apariencia de los conflictos específicos dentro de su filosofía no son esporádicos, sino más bien casi sistemáticos -en sentido metodológico- se puede incluso describir esta dinámica como conflictividad, en el sentido productivo del término. Uno de los méritos de esta aproximación es que ayuda a encontrar los límites de ciertos tipos de explicación. Por ejemplo, pretender que una crítica genealógica pueda agotar la posibilidad de sentido llevada a cuestas por la ética, sería permitir un gran reduccionismo.

Debemos también agregar que hay muchos tipos de conflictos dispersos a lo largo de los trabajos de Ricœur y que no hay una única llave universal para entender cada uno con sus propias particularidades. En realidad, es preciso que sean analizados caso por caso. No obstante, esto no nos impide establecer una cierta tipología. Hay, por ejemplo, conflictos simples (los que se encuentran entre dos teorías diferentes, como en el caso de la hermenéutica arqueológica versus la teleológica) y conflictos complejos, con múltiples polos de conflictividad - esto sucede cuando hay más de dos teorías confrontadas entre sí-. Así también, cambia la posición en la que se sitúa Ricœur frente a la especificidad de cada conflicto o, dicho de otro modo, la forma en la que Ricœur los aborda. ¿Cómo lidia él, pues, con el acaecimiento de conflictos?

Debemos hacernos, primero, las siguientes preguntas: ¿debemos estar satisfechos con entender el conflicto como la mera oposición entre distintas teorías? ¿Esto es todo lo que nuestro filósofo tiene que ofrecernos? Y hemos de responder, claro que no. Si fuera esto así, no escaparía a los cargos de eclecticismo que denuncian en él algunos de sus críticos. Y, si es que pretendemos aquí iluminar de algún modo la filosofía de Paul Ricœur, tenemos que entender simultáneamente 1) cuáles fueron sus intenciones iniciales, a qué aspiraba al inicio de su carrera filosófica y cómo estas intenciones cambiaron al paso del tiempo; pero también, 2) cuáles fueron los procedimientos metodológicos específicos que utilizó en todos sus trabajos. Para lograr ello, se debe tomar en consideración al opuesto dialéctico del 
conflicto, esto es, la conciliación, y mostrar qué lugar ocupa esta noción en su filosofía.

Inicialmente, el filósofo francés no evitó establecer preguntas ontológicas específicas sin haber conducido una investigación antropológica ${ }^{8}$ previa. En sus lecturas de la filosofía de Karl Jaspers, diagnostica un cierto tipo de paradoja; dicha filosofía, remarca, tiene dos centros (foyers): la Existencia y la Trascendencia. El primero está caracterizado por la libertad y el último por su conexión al Ser en cuanto tal. Hay una cierta tensión entre ambos; se puede incluso decir que hay un conflicto. Sin embargo, nuestro filósofo sostiene que lo que está separado en el pensamiento puede ya haber estado secretamente reconciliado 9 . Y esta reconciliación sería, en realidad, ontológica. Esta es la manera como el joven Ricœur (en este punto, junto a Mikel Dufrenne) piensa la conexión entre fe religiosa, existencia y filosofía. Es alguna forma de ser reconciliado (percibido por el corazón humano) lo que, de acuerdo con Ricœur y Dufrenne, constituiría la solución a la filosofía de Jaspers. Entonces, de acuerdo con ello, sin importar cuán fragmentario pueda ser un pensamiento, aquel que exprese esta forma podrá vislumbrar, a través de la contemplación ${ }^{10}$, la reconciliación interna que provee ya la religión ${ }^{11}$.

\footnotetext{
${ }^{8}$ El cual no es el caso en sus últimas obras, (Ricœur, 1990), donde lo ontológico es pospuesto al último estudio - esto es una consecuencia de las grandes, aunque incompletas, mediaciones que constituyen la famosa voie longue-.

9 “Aquello que para el pensamiento es separado, ¿no está de algún modo ya reconciliado? (...) tal vez una filosofía definitivamente desgarrada es imposible y la paradoja tiene siempre por telón de fondo una unión y una participación, del orden de la acción y del orden del sentimiento" / "Ce qui pour la pensée est séparé n'est-il pas d'une certaine façon réconcilié ? (...) peut-être qu'une philosophie définitivement déchirée est impossible et que le paradoxe a toujours pour toile de fond une union et une participation, de l'ordre de l'action et de l'ordre du sentiment" (Ricœur, 1947, p. 379). Para una explicación más detallada, véase la sección completa "La déchirure et la conciliation" (Ricœur, 1947, pp. 379-393).

${ }^{10}$ La palabra de Dios llega a ser la real mediación entre la Existencia y la Trascendencia. En cuanto a la contemplación, Ricœur y Dufrenne afirman que este concepto tiene, en la filosofía de Jaspers, el mismo rol que la Aufhebung en el sistema de Hegel (Ricœur, 1947, p. 384).

${ }^{11}$ Esto tiene una íntima conexión con la noción de misterio, tal y como aparece en la filosofía de Gabriel Marcel (Ricœur, 1948).
} 
Esta posición no dura mucho en la producción filosófica de Ricœur ${ }^{12}$. Incluso sus trabajos sobre religión y filosofía de la religión evolucionan de maneras radicalmente distintas a esta ${ }^{13}$, puesto que llega a ser inclusive más prudente en lo que concierne a la distinción entre los dominios de la filosofía y la religión. Honestamente, no creemos que él haya querido ser considerado un filósofo cristiano ${ }^{14}$. Él fue un filósofo y, además, fue cristiano. Pero no creemos que realmente quisiera probar, en sus últimas obras, una reconciliación en el ser ambos, ni la existencia de Dios, lo cual le es dado como cierto desde ya en su fe. Podemos encontrar lo esencial de su posición en el artículo "Un philosophe protestant: Pierre Thévenaz" donde Ricœur, hablando sobre Thévenaz, resume realmente lo que llegaría a ser luego su propia posición:

\footnotetext{
${ }^{12}$ Incluso si esto es afirmado aun en Le volontaire et l'involontaire ("Este estudio de lo voluntario y de lo involuntario es una contribución limitada a un propósito más vasto, el cual buscaría el alivio de una ontología paradójica en una ontología reconciliada" / "Cette étude $d u$ volontaire et de l'involontaire est une contribution limitée à un dessein plus vaste qui serait l'apaisement d'une ontologie paradoxale dans une ontologie réconciliée" (Ricœur, 1950, p. 22)) donde trata de establecer una conciliación entre las filosofías existenciales de Jaspers y Marcel, con el método eidético de Husserl.

${ }^{13}$ Para un estudio más amplio de este tema, en las muchas maneras en las que la religión y la filosofía fueron importantes para Ricœur, véase: Vincent, 2008.

${ }^{14}$ Esto constituye aún otro debate polémico entre los intérpretes de Ricœur; hay muchos escritos de Ricoeur en los que la filosofía y los estudios religiosos realmente se superponen. Cf. por ejemplo, "La règle d'or en cuestión" en Lectures 3 (1994), un ensayo notable en el que trata de proponer una mediación entre el imperativo categórico kantiano y la regla de oro. Sin embargo, creo que la seriedad de la labor filosófica condujo a Ricoeur a tomar realmente las cuestiones filosóficas como tales $-\mathrm{y}$, por lo tanto, tomar como tal la brecha entre la crítica y la convicción - siendo la fe evidentemente una cuestión de convicción. Esta debe ser la razón por la cual, a pesar de que la versión inicial de Sí mismo como otro (es decir, las Gifford Lectures) inicialmente terminaban con dos estudios teológicos (ahora publicados en la última versión de Amour et Justice [2008]), Ricœur decidió reemplazarlos por su petite éthique (estudios VII a IX), seguido por el décimo estudio "Vers quelle ontologie", donde finalmente se declara a sí mismo como filosóficamente agnóstico. "No he incluido estas conferencias en Soi-même comme un autre, con el fin de mantenerme fiel al antiguo pacto en virtud del cual establecí que las fuentes no filosóficas de mis convicciones no serían mezcladas con los argumentos de mi discurso filosófico" / "Je n'ai pas repris ces deux conferences dans Soi-même comme un autre, afin de rester fidèle au pacte ancien en vertu duquel les sources non philosophiques de mes convictions ne seraient pas mêlées aux arguments de mon discours philosophique" (Ricœur, 1995c, pp. 78-79). Esto, por supuesto, no quiere decir que no podamos sacar conclusiones filosóficas de sus obras religiosas y viceversa; sin embargo, creo que debemos pensar estos ámbitos como siendo entre sí lo más autónomos posibles en el pensamiento de Ricœur.
} 
La fe, la fe en la Cruz de Cristo, como él la comprende y la vive en un contexto protestante eclesial y dogmático, no la condena a la no-filosofía: por el contrario, la entrega a la autonomía de la reflexión. Pero esta libertad de filosofar que le viene dada por su fe, no la consume tampoco al acuerdo, a la armonía entre los enunciados de su filosofía y de su fe: la filosofía, según él, no tiene la obligación de hablar de Dios, y mucho menos desde el punto de vista de Dios; veremos también que alcanza su autenticidad cuando ella confiesa su impotencia, o aún mejor, su renuncia para convertirse en la filosofía de lo divino, en la filosofía divina. A una filosofía divina se le opondrá constantemente una filosofía responsable ante Dios, una filosofía en la que Dios no es más el objeto supremo de la filosofía, sino en la que está implicado a título de polo de llamada y de respuesta del acto filosófico mismo. ${ }^{15}$

Debemos señalar que Ricœur pone énfasis, desde el comienzo, en la importancia de la autonomía. Esto no quiere decir, como una lectura cuidadosa de sus análisis de filosofía moral kantiana mostraría (en textos como Sí mismo como otro y "Une obéissance aimante" en Lectures 3), una absoluta autonomía, porque en el contexto de la filosofía ricœuriana la autonomía del sujeto está siempre confrontada con la restricción del otro (esto revela una cierta pasividad en nosotros) y también porque el sujeto actuante está propenso a interpretar y transformarse a sí mismo por el acto de leer, lo que revela nuestra apertura a apropiarnos activamente de las distintas formas de vida que estuvieron ahí antes de nosotros, pero que podemos activamente imitar a nuestra propia manera. Esto es, por ejemplo, "la forma cristiana de vida", la cual es una "forma de vida legítima" -que no es necesariamente una "forma de pensar", al menos al hacer filosofía, en el sentido de que el filósofo no debe "probar filosóficamente" su fe-. Y esta teoría de la lectura, a la que prestaremos ampliamente atención en este artículo, no nos impide pensar una posible apropiación de otras formas de

\footnotetext{
15 "La foi, la foi dans la Croix du Christ, telle qu'il la comprend et la vit dans un contexte ecclésial et dogmatique protestant, ne le condamne pas à la non-philosophie : elle le rend au contraire à l'autonomie de la réflexion. Mais cette liberté de philosopher à quoi il est remis par sa foi, il ne la dépense pas non plus à accorder, à harmoniser les énoncés de sa philosophie à ceux de sa foi : la philosophie, selon lui, n'a pas la charge de parler sur Dieu, encore moins du point de vue de Dieu; on verra même qu'elle atteint son authenticité quand elle avoue son impuissance, mieux, son renoncement à devenir philosophie du divin, philosophie divine. A une philosophie divine il opposera constamment une philosophie responsable devant Dieu, une philosophie où Dieu n'est plus l'objet suprême de la philosophie, mais où il est impliqué à titre de pôle d'appel et de réponse de l'acte philosophique lui-même" (Ricœur, 1994: 246).
} 
vida: la estoica o la epicúrea, la teorética expresada en la famosa práctica de la contemplación o la vita activa que ha sido magníficamente fomentada por Hannan Arendt en La condición humana. De cualquier modo, algo que a Ricœur nunca le faltó fue honestidad (Redlichkeit); siempre asumió su tradición y prácticas cristianas sin querer imponerlas de ningún modo, en absoluto -lo que se presta a algunas críticas, como la triste acusación de Badiou de que "tal y como Descartes, Ricoeur avanza enmascarado" 16 - una acusación que vuelca violentamente la filosofía de la sospecha contra Ricœur mismo, de manera del todo injusta ${ }^{17}$. No obstante, es precisamente porque se han presentado estos tipos de acusaciones que debemos, en nuestra opinión, tomar los trabajos filosóficos de Paul Ricœur desde su carácter estrictamente filosófico.

Sin embargo, si nuestro filósofo renuncia, en efecto, al tipo de reconciliación religiosa que, como vimos, quería asignar al inicio de su carrera a los trabajos de Jaspers, asume, sostendremos, un tipo distinto de figura de conciliación. Esto llega a ser, en nuestra opinión, un cierto enfoque metodológico que está conectado con la emergencia de sentido que hemos analizado antes. Si consideramos la teorización del conflicto en el dominio interpretativo teórico, la consecuencia es que no habrá soluciones hermenéuticas universales. Lo que sí tenemos es un gran grupo de teorías que, al parecer, conciernen a los mismos fenómenos, pero que leen esos fenómenos de maneras completamente diferentes. Si una teoría tiene toda la razón, la otra debería, eo ipso, estar completamente mal. A menos que

\footnotetext{
16 "tout comme Descartes, Ricour s'avance masqué" (Badiou, 2003).

${ }^{17}$ La acusación dice: “(...) lo que Ricœur intenta obtener realmente a través de medios sofísticos de análisis conceptual no es nada menos que una victoria. La victoria de la visión cristiana del sujeto histórico contra el que hoy en día se impone cada vez más y que es de procedencia principalmente judía, pero no únicamente" / "[...] ce que Ricœur tente en réalité d'obtenir par les moyens sophistiqués de l'analyse conceptuelle n'est rien moins qu'une victoire. La victoire de la vision chrétienne sur le sujet historique contre celle qui aujourd'hui s'impose de plus en plus et qui est de provenance principalement juive, mais pas uniquement" (Badiou, 2003, p. 19). Badiou está acusando a Ricœur en el contexto de La mémoire, l'histoire, l'oubli; la disputa se dirige sobre todo al controversial último capítulo, acerca de la posibilidad del olvido. Sin embargo el rol de Badiou como un maestro de la sospecha en lo que concierne a las presuntas motivaciones de Ricœur, podría proyectar ensombrecer la totalidad de la obra de nuestro filósofo - no habría una cuidadosa distinción entre los dominios filosófico y religioso en sus obras-. Una réplica a los cargos de Badiou la encontramos en Abel (2006).
} 
sea posible pensarlas juntas. Remarco la importancia de este pensar juntos porque es lo que nos ayuda a evitar el pensamiento unidimensional -el muy alabado diálogo que el autor francés profesó-. Esto puede ser visto ciertamente como una de las consecuencias de la sobredeterminación de símbolos. A través de los símbolos mismos, podemos prever la conciliación de los diferentes tipos de hermenéutica. O, si no una verdadera conciliación, porque no siempre, como veremos, es el caso, por lo menos la promoción de una tercera posición. ¿Qué significa esto, si no una forzada yuxtaposición? ¿En qué medida el pensamiento de Ricœur escapa del eclecticismo? Lo hace porque su planteamiento es doble. Si, por un lado, trata de participar en los debates teóricos de su tiempo -y haciéndolo muestra que un planteamiento reflexivo siempre está situado, siempre está inserto en una cultura específica; los autores y las constelaciones de las teorías que aparecen en el cuerpo de su trabajo son los reflejos del mundo cultural y filosófico en el que él vivió-, por otro lado, solo citó a los autores y a las teorías que consideró útiles, pertinentes, para el desarrollo de la argumentación filosófica que estaba buscando:

Es a menudo en los restos del tema precedente en los que avizoré la urgencia de un nuevo tema. Esto se da en mi relación con el psicoanálisis, ya que verdaderamente es de la Symbolique du mal que procede l'Essai sur Freud. Habiendo adoptado una línea que era básicamente el de la fenomenología de la religión, cerca de Eliade, tenía la sensación de que, en Freud, Nietzsche y Marx, había un pensamiento opuesto con el cual debía explicarme ${ }^{18}$.

Como fácilmente podemos inferir por la cita de anterior, Ricœur hizo esto porque su empeño filosófico (pese a sus convicciones personales) era sincero. No importó cuán convencido haya estado de la exactitud de un específico punto de vista, no podía tomarlo por supuesto sin ponerlo a prueba, es decir, sin confrontarlo con la panoplia de diferentes interpretaciones de los mismos fenómenos. Esto fue, para él, uno de los roles de la filosofía crítica. Fue, en cierto sentido, una forma de retribuirle a la fuerza de cada argumento que usó

\footnotetext{
18 “C'est souvent dans les restes du sujet précédent que j'ai vu l'urgence d'un autre thème. Cela est vrai de mon rapport à la psychanalyse, puisque c'est véritablement de la Symbolique du mal que procède l'Essai sur Freud. Ayant adopté une ligne qui était en gros celle de la phénoménologie de la religion, proche d'Eliade, j'avais bien le sentiment que, chez Freud, Nietzsche et Marx, il y avait une pensée adverse avec laquelle je devais m'expliquer" (Ricœur, 1995a, p. 119).
} 
y a la inteligencia de sus adversarios. Creo que podríamos mencionar aquí, mutatis mutandis, algún tipo de pensamiento amplio (erweiterte Denkart), en el sentido dado por $\mathrm{Kant}^{19}$.

Si extrapolamos este marco teórico a la totalidad de la obra de Ricœur, lo que encontraremos será una filosofía fragmentada pero que procede a fondo mediando los conflictos que tienen lugar dentro de ella y que se repiensan juntos. Entonces, el proceder creativo del método de Ricœur no se detiene en la antitética, sino que prosigue a una cierta dialéctica, incluso si es para ser una muy diferente a la de la más famosa de las dialécticas, la hegeliana. En efecto, esta dialéctica no produce una síntesis, pero sí pasajes sin fin de un polo a otro. Estos pasajes o mediaciones son, en opinión nuestra, las propias hipótesis de Ricœur acerca de la conciliación entre teorías totalmente distintas pero que enriquecen su percepción si se unen y pueden explicar con éxito lo que está en juego en los muchos dominios filosóficos a

\footnotetext{
${ }^{19}$ Le debo a los brillantes artículos de Mário Jorge de Carvalho (2004 y, especialmente, 2007) los análisis de esta noción kantiana. Muchos otros aspectos de mi aproximación filosófica han estado influenciados por sus análisis de Aristóteles, Heidegger, Kant y Platón. Los textos citados articulan la conexión entre la noción de "egoísmo lógico" en Kant y el modo como se puede escapar de él-recurriendo a los principios de aufgeklärte Denkart, erweiterte Denkart y konsequente Denkart-. La noción de la ampliación del pensamiento tiene que ver precisamente con evitar la injustificada exclusión de las perspectivas alternativas. La consideración de esos puntos de vista alternos, en cualquier sentido, no implica una falta de autonomía en la elaboración del propio juicio. Lo que pretende, precisamente, es eliminar el vicio de la creación de puntos sesgados en la propia consideración ante un problema dado, en la formación propia de un juicio correcto. Además, lo que está en juego en este punto de la filosofía kantiana no es exclusivamente el hecho de que la perspectiva viene de alguien que no soy yo -lo que importa es la plausibilidad de esa perspectiva-. El hecho que viene, por decirlo así, "de afuera", que se ha producido en un lugar distinto a mi propio reflejo sobre las cosas, no es la característica más importante de este proceso. Más bien, es una posibilidad plausible para mi propio punto de vista que debería considerar. Del mismo modo, podemos apreciar, mutatis mutandis, la preocupación de Ricœur por la apropiación de otras perspectivas. Él leyó a Freud, pero no porque fuese ecléctico, ni tampoco porque no tuviese una única filosofía y estuviese obligado a armar un rompecabezas con otros filósofos. Lo leyó, más bien, porque sintió que tenía que confrontarse a sí mismo con esa perspectiva, para intentar entender realmente de qué estaba hablando. Quiero aclarar que no estamos afirmando necesariamente que Ricœur estaba dispuesto a cumplir con todas las prerrogativas de un pensamiento exitosamente ampliado a modo kantiano -pero sostenemos que esto implica que su proyecto y su metodología tuvieron similitudes con un proyecto formal, y que intentó, con sus modestos medios, lograr, tanto como humanamente le fuera posible, un proyecto de ese tipo, siguiendo su propia y particular forma dialéctica-.
} 
los que el filósofo ha llevado a cabo sus investigaciones. Para explicar este proceso, siempre riguroso y fértil, a veces usó la metáfora del arbitraje. Esta restricción metodológica fue tomada muy en serio:

En el fondo, una cuestión me preocupaba verdaderamente: la consistencia de mi discurso; para mí, se trataba antes que todo de resolver mis propias contradicciones, las tensiones entre las diversas influencias; mi problema siempre fue saber si yo estaba construyendo falsas ventanas, si lo que yo hacía no era más que un compromiso, o si era en realidad la propuesta de una tercera vía capaz de mantener la ruta ${ }^{20}$.

En esta cita podemos ya vislumbrar a lo que él se refería con el procedimiento de la conciliación -la rigurosa y alternativa solución filosófica a las aporías presentadas por los polos opuestos mostrados en el conflicto-. Esto introduce otro paso significativo hacia el comprehender la metodología de Ricœur. Buscaba construir alternativas filosóficas reales a los problemas con los que se enfrentaba. En este punto, dijo que no quería sus posiciones filosóficas para llegar a nada más que a "compromisos". Sin embargo, debemos remarcar que esto es solo importante para los núcleos meramente teóricos de su método filosófico -no en su filosofía práctica-. A este artículo no le concierne esa importante dimensión de la producción de Ricœur; dejaremos una explicación completa de ello para un trabajo futuro, pero podemos adelantar lo siguiente: en meros términos teóricos, a veces Ricœur adopta cierta posición constructivista, es decir, algunos de los conflictos que analiza están solo en conflicto en el desarrollo de su método. Hace que las fuerzas antitéticas choquen, para así mostrar que la mejor aproximación va más allá de dicho choque. Es así que algunas de las confrontaciones que tienen lugar en el nivel teórico de sus libros están ahí porque tienen que estar ahí si Ricœur tiene éxito al demostrar su tesis. Hay, pues, un cierto grado de constructivismo de su método teórico.

En el vasto dominio de la filosofía práctica, sin embargo, él no es y no puede ser constructivista. Cada vez que trata con la estructura de la necesidad de la acción, del l'homme agissant et souffrant, no está construyendo los

\footnotetext{
20 "Au fond, une chose me préoccupait vraiment: la consistance de mon discours; pour moi, il s'agissait avant tout de résoudre mes propres contradictions, les tensions entre les influences diverses; mon problème était toujours de savoir si je construisais de fausses fenêtres, si ce que je faisais n'était pas qu'un compromis, ou si c'était réellement la promotion d'une position tierce, capable de tenir la route" (Ricœur, 1995a, p. 118).
} 
conflictos; simplemente, no puede escapar de ellos. Lo único que puede hacer es lidiar con ellos, y enfrentarse con el sufrimiento humano y con la inexorabilidad de la acción. En ese caso, con las soluciones que nos plantea para los problemas prácticos con los que se enfrenta-ya sea en los dominios de la ética aplicada, las luchas pertenecientes al reconocimiento o los problemas históricos relacionados con la memoria y el olvido-, lo que trata de hacer es resolver esos problemas. No está muy ansioso por ampliar su perspectiva cuando está preocupándose por la paz, la caridad o la sobreabundancia. En este contexto especifico usa la noción de compromis en un muy distinto sentido, derivado de la obra de Luc Boltanski y de Laurent Thévenot. De hecho, ser capaz de llegar a un acuerdo por medio del compromiso es una de las vías que Ricœur propone cuando analiza el dominio de la acción social. Con esta distinción en mente -el compromiso en el sentido de Boltanski y Thévenot es aplicable a la esfera de la acción social ${ }^{21}$, el compromiso en el mero nivel teórico es una falsa alternativa que sugiere el abandono de los propios principios, algo que debe ser cuidadosamente evitado-, podemos volver al principal punto que nos compete: la metodología de Ricœur.

Uno de los puntos más interesantes, sin embargo, es que nuestro filósofo admite, él mismo, que las mediaciones que tienen lugar en su filosofía son frágiles y provisionales, es decir, que siempre podemos negar la legitimidad de lo establecido como una conexión particularmente teórica y reformular todo el enfoque con base en un cierto dominio teórico. Él, con frecuencia, usa expresiones como "médiations toujours fragiles et provisoires" o "le style de médiation incomplète entre positions rivales" ${ }^{22}$. Esta es la razón

\footnotetext{
${ }^{21}$ Con la aparición de la noción de compromis, que ha sido discutida varias veces en los trabajos posteriores de Ricœur (Ricœur, 1995b, y 2004). Véase: Boltanski y Thévenot (1991), y también, para una apología a esta noción, en la entrevista Ricœur (1991).

22 "Una forma de despejar el camino entre estos dos extremos es tomar por guía del pensamiento meditativo la dialéctica entre el amor y la justicia. Por dialéctica me refiero aquí, de una parte, el reconocimiento del desequilibrio inicial entre los dos términos y, de otra parte, la búsqueda de mediaciones entre los dos extremos -mediaciones, digámoslo inmediatamente, siempre frágiles y provisorias" / "Une manière de se frayer la voie entre ces deux extrêmes est de prendre pour guide d'une pensée méditante la dialectique entre amour et justice. Par dialectique, j'entends ici, d'une part, la reconnaissance de la disproportion initiale entre les deux termes et, d'autre part, la recherche de médiations entre les deux extrêmes, - médiations, disons-le tout de suite, toujours fragiles et provisoires" (Ricoeur, 2008, p. 15). Y también: "Me atrevo a creer, en efecto, que mi propio estilo de mediación incompleta entre posiciones opuestas expresa una limitación resultante de la historia misma
} 
por la que, en sus obras posteriores, Paul Ricœur invita constantemente a los lectores a releer sus obras con diferentes pistas hermenéuticas (Ricœur, 1990). Además, esto fue muy importante para la aparición de nuevos sentidos concernientes a las lecturas de su propia obra. La conclusión de Tiempo y narración, escrita muchos meses después de escribir el tercer volumen, plantea nuevos puntos de vista sobre la totalidad (los tres tomos) de esta obra, solo posible a través del continuo acto de reinterpretación de sus escritos previos, siendo esta la riqueza de la filosofía, especialmente en las obras monumentales que se han convertido en clásicas. En ellas, nada es vago o fácilmente identificable, nada objetivo, en un sentido positivista. Todo está dispuesto para la felicidad propia de la búsqueda del nuevo sentido. Entonces, las variadas soluciones de conciliación entre distintas teorías no son sino posibilidades de sentido que el filósofo propone pero que nunca completa, ni son nunca completamente correctas. Están expuestas, más bien, al juicio del lector y a su eventual reformulación. Esto es particularmente evidente en los famosos análisis narrativos de Tiempo y narración: "El momento en el que la literatura alcanza su máxima eficiencia es quizá aquel en el que pone al lector en la posición de recibir una solución para la que él mismo debe encontrar las preguntas apropiadas, aquellas que constituyen el problema estético y moral establecido por la obra"23.

de esta problemática filosófica considerada a largo plazo. Todos pertenecemos, en mi opinión, a la era poshegeliana del pensamiento y nos conducimos al difícil trabajo de duelo respecto del sistema. Este trabajo de duelo está marcado por la alternancia entre lo que Karl Jaspers llama sistematicidad sin síntesis final y una forma de pensamiento deliberadamente fragmentaria. Yo me comprendo a mí mismo como si fuera más bien del segundo estilo y como si no cumpliera con primero más que a través del segundo. Yo caracterizaría la época de larga duración que nos envuelve y nos desborda como sistematicidad herida, así como llegué a hablar para mí-mismo de Cogito herido" / "J'ose croire en effet que mon style propre de médiation incomplète entre positions rivales exprime une contrainte issue de l'histoire même de cette problématique philosophique considérée sur la longue durée. Nous appartenons tous, à mon avis, à l'ère poshégélienne de la pensée et menons tous, à notre façon, le difficile travail de deuil à l'égard du système. Ce travail de deuil se marque par l'alternance entre ce que Karl Jaspers appelait une systématicité sans synthèse finale et un mode de pensée délibérément fragmentaire. Je me comprends moi-même comme relevant plutôt du second style et comme ne satisfaisant au premier qu'à travers le second. Je parlerai pour caractériser l'époque de longue durée qui nous enveloppe et nous déborde de systématicité brisée, comme il m'est arrivé de parler pour moi-même de Cogito blessé" (Ricœur, 1987, p. 2).

23 "Le moment où la littérature atteint son efficience la plus haute est peut-être celui où elle met le lecteur dans la situation de recevoir une solution pour laquelle il doit lui-même 
En esta cita, Ricœur está suscribiendo la posición de H.R. Jauss (1978). Creemos que podemos aplicar esta noción a la lectura de textos filosóficos también. La capacidad para responder las preguntas correctas se da al inicio de cualquier esfuerzo filosófico, pero también al inicio de la revisión de cualquier texto o teoría. Uno de los factores que debemos tomar en cuenta es el siguiente: nunca llegaremos a la formulación de un sistema completo. La incompletitud (inachèvement) es inevitable cuando se hace filosofía, como en cualquier intento humano, o al menos, como en cualquier otra expectativa teórica. Ricœur estaba muy consciente de esto. Pero la creación del sentido, y el perpetuo desciframiento de los fenómenos que nos hacen pensar (como símbolos -"le symbole donne à penser") no se detiene cuando un trabajo filosófico está escrito. En efecto, estos sentidos son también vástagos de los lectores. Es por eso que la lectura y la discusión de la vasta obra de este gran filósofo es una tarea fecunda.

Esto nos lleva al punto desde donde la emergencia del conflicto se presenta una vez más. Si la tarea del filósofo es pensar críticamente, en el sentido de la crítica asumida desde Kant hasta el posterior desarrollo de la teoría crítica de Frankfurt, una pizca de sospech $a^{24}$ es siempre parte importante de toda lectura hermenéutica. Para Ricœur, es en el acto de la lectura en el que una obra encuentra su completitud -estas están hechas para ser leídas y, así también, es a través del lector que el círculo de la mímesis alcanza su completo significado, cuando la lectura refigura la experiencia del lector-. Sin embargo, aunque presuponga una cierta fusión de horizontes (Horizonsverschmelzung) en el sentido gadameriano, aunque el mundo creado por la literatura intercepte el mundo del lector, la intersección no siempre es tan fácil. Interpretar activamente un texto significa pensar junto con él, "probar

trouver les questions appropriées, celles qui constituent le problème esthétique et moral posé par l'œuvre" (Ricœur, 1985, p. 254).

${ }^{24}$ Ricœur habla explícitamente acerca de la responsabilidad del lector, especialmente en el caso de las narrativas en las que el narrador no es digno de confianza (Ricœur, 1985, pp. 236-238). A este nivel de compromiso, la lectura vigilante puede ser transpuesta, mutatis mutandis, a la filosofía, al comprometer al filósofo al ejercicio de la crítica. Agradezco a Allison Scott-Bauman por haber sugerido la introducción de la noción de la sospecha en el modelo dialéctico de conflicto y conciliación que estoy planteando (Scott-Baumann, 2009). Cuando digo "un poco de sospecha" no estoy, obviamente, queriendo emsombrecer las intenciones del autor, como Badiou parece hacer con Ricœur. Es decir, la sospecha no debería ser extrema -no tenemos que olvidar la dialéctica entre la simpatía y la sospecha, como Wiercinski planteó-. 
activamente lo que parece débil o poco claro, preguntar continuamente si el filósofo se corresponde con los reclamos que presenta, imaginar cómo una posición podría responder mejor a las objeciones que a aquellas cuestiones planteadas en mismo el texto" (Pippin, 2008, p. 33)

En nuestra opinión, esto es lo que todo el tiempo está haciendo Ricœur. Muestra que el acto hermenéutico de la apropiación se debe dar mediante el ejercicio de la crítica, confrontarse a sí mismo con los actuales problemas filosóficos, del modo explicado anteriormente. Esto corresponde, aproximadamente, al aprendizaje de la filosofía ex principis (Kant, 1978, B 864) (opuesta a los ex datis, según la famosa distinción de Kant) y al coraje del sapere aude en plena "edad hermenéutica de la razón", para citar el famoso título de Jean Greish. Es este fenómeno, pensamos, el que convierte a la tradición en innovación, lo que corresponde a otro modo de expresar un "kantismo post-hegeliano" - efectuado Selbstdenken desde la dialéctica-. Es aquí que la torpe forma de Ricœur para designar su filosofía, como kantismo post-hegeliano, merece cierta atención:

El kantismo que quiero desarrollar ahora tiene que ver, paradójicamente, más con hacer que con repetir; ello sería algo así como un kantismo posthegeliano (...) cronológicamente, Hegel viene después de Kant; pero nosotros, lectores tardíos, vamos del uno al otro; en nosotros algo de Hegel superó a algo de Kant; pero algo de Kant superó a Hegel, porque somos post-kantianos. En mi opinión, es este intercambio que estructura aún el discurso filosófico hoy en día. Es por eso que la tarea es pensarlos siempre mejor, pensarlos juntos, el uno contra el otro, y el uno por el otro. Incluso si empezamos a pensar otra cosa, este "mejor pensar en Kant y Hegel" pertenece, de una manera u otra, al "pensar de forma diferente que Kant y Hegel ${ }^{26}$.

\footnotetext{
${ }^{25}$ En este pasaje, Pippin se refiere a la metodología de Kant, y afirma que esta es la mejor manera de leer un texto filosófico - esto se acerca mucho al método de Ricœur-.

26 "Le kantisme que je veux maintenant développer est, paradoxalement, plus à faire qu'à répéter ; ce serait quelque chose comme un kantisme post-hégélien (...) chronologiquement, Hegel vient après Kant; mais nous, lecteurs tardifs, nous allons de l'un à l'autre; en nous quelque chose de Hegel a vaincu quelque chose de Kant; mais quelque chose de Kant a vaincu Hegel, parce que nous sommes post-kantiens. A mon avis, c'est cet échange qui structure encore le discours philosophique d'aujourd'hui. C'est pourquoi la tâche est de les penser toujours mieux, en les pensant ensemble, l'un contre l'autre et l'un par l'autre. Même si nous commençons à penser autre chose, ce "mieux penser Kant et Hegel " appartient, d'une manière ou de l'autre, à ce "penser autrement que Kant et Hegel "" (Ricœur, 1995a, pp. 402-403).
} 
De algún modo, este pasaje contiene muchas de las características que hemos enfatizado en este artículo. Tenemos, así, la noción del pensar juntos (penser ensemble), el énfasis en el edificio activo de la propia filosofia: "un kantisme plus á faire qu 'á répéter", el movimiento específico de su dialéctica: "nous allons de l'un á l'autre", la tendencia hacia algún tipo de progreso en el propio esfuerzo de pensar: "la tâche est de les penser toujours mieux" y también las diferentes formas en que los conflictos podrían desplegarse: "l'un contre l'autre" y/o "l'un par l'autre". Del mismo modo, y decisivamente, la marca de la originalidad y de la novedad provocada por los procedimientos específicos de la conciliación: "ce penser autrement que Kant et Hegel". Donde encontramos a Kant y a Hegel, podríamos tener a Aristóteles y Kant (en la petite éthique de Soi-même comme un autre), Gadamer y Habermas, o muchos, muchos otros, en cada uno de los distintos conflictos que Ricœur ha mediado a lo largo de su extensa carrera.

¿En qué consiste la diferencia entre la dialéctica de Ricœur y la dialéctica hegeliana? Ambas expresan un cierto método, mediante el cual la forma y el contenido no pueden ser considerados del todo separados. Incluyeron, ambos filósofos, el momento negativo. Sin él, sus filosofías no serían productivas. La gran diferencia está en la posibilidad de formar un sistema en el que la razón actúe como gran unificadora o, de otro modo, la posibilidad del conocimiento absoluto. Esto es imposible en Ricœur, como lo es en la mayor parte de la filosofía contemporánea. Uno de los modos de expresarlo es el siguiente: la dialéctica de Ricœur es una "dialectique à synthèse ajournée" como ha dicho él mismo en Historia y verdad. La posibilidad del saber absoluto, como encontramos en La fenomenología del espíritu o en la Enciclopedia de las ciencias filosóficas, es totalmente rechazada. Pues el kantismo de Ricœur lo obliga a rechazar cualquier autorepresentación (Selbst-Darstellung) de lo Absoluto ${ }^{27}$. Él es kantiano precisamente porque acepta los límites del razonamiento humano. Esta es una filosofía de lo finito, de los límites. Pero también es, al mismo tiempo, una filosofía del empeño, de la acción y de la capacidad. "El hombre es la alegría del sí en la tristeza de lo finito"28.

Admitirlo, apropiarse de ello, significaría renunciar a Hegel. Considerando, entonces, que aún así seamos descendientes de Hegel, no

\footnotetext{
${ }^{27}$ Véase: "Le statut de la Vorstellung dans la philosophie hégélienne de la religion" (Ricœur, 1969).

28 "L'homme c'est la joie du oui dans la tristesse du fini" (Ricœur, 1960, p. 156).
} 
somos hegelianos tout court. Después de todo, no pensamos igual que Hegel, sino después de $\mathrm{Hegel}^{29}$. Si tuviésemos que encontrar, pues, el proceso de Aufhebung de Ricœur, este sería enteramente provisional ${ }^{30}$. En realidad, nos inclinamos a decir que en muchos momentos de su filosofía el punto de partida de Ricœur es en realidad el momento negativo. Ricœur va del conflicto a la conciliación; pero luego, cuando sugiere las diferentes claves hermenéuticas habilitadas para desencadenar otras posibilidades de sentido contenidas en sus propios trabajos, está reintroduciendo el conflicto en las bien-dispuestas conciliaciones que ya había establecido. A ello justamente debemos el título de este artículo, "Del conflicto a la conciliación y viceversa". La dialéctica de Ricœur tiene conflictos en sus puntos de partida y de llegada. Los conflictos nos ponen nuevamente en contacto con los verdaderos problemas filosóficos. Nos muestra cuán lejos -0 , más bien, las provisionales consecuencias que hemos establecido- estamos de comprender el completo sentido de los fenómenos que queremos comprender. La producción de nuevos conflictos y nuevas conciliaciones es el proceso mediante el cual crece el campo de su filosofía, ayudando a resolver problemas teóricos y prácticos. En este esfuerzo, Ricœur podría y debería ser ayudado por el lector comprometido para que su pensamiento permanezca vigente.

Nos atreveremos a resumir provisionalmente, y en pocas palabras, este procedimiento metodológico del que hemos estado hablando. El acto mismo de leer adquiere una posición particular en la metodología de Ricœur. Él era tanto un erudito, como un pensador original. Su trabajo se enriqueció con la lectura-lectura de su propia filosofía, lectura de los antiguos, de los modernos y de sus compañeros contemporáneos- con el objetivo de desarrollar un pensar juntos y un pensar ampliado. Este acto riguroso de lectura-mediante el cual formamos nuestra perspectiva y ponemos a prueba al contrastarlo con otras posibilidades, y que condujo a Ricœur a sus teorías hermenéuticas

\footnotetext{
${ }^{29}$ Consúltese el capítulo "Renoncer à Hegel”, (Ricœur, 1885, pp. 282-299). Pensar después de Hegel significa interpretar sus escritos, haciendo lo mismo que muchos intérpretes, desde Bruno Bauer y Karl Marx hasta Honneth y Pippin, incluso si renunciamos al sistema. Esto también implica cierto "travail de deuil", para que cuando no podamos ser hegelianos nunca más, nos quede el profundo sentido de la pérdida -y es así que todos los puntos de vista hegelianos deben ser re-elaborados, como Honneth y Ricœur hicieron con el reconocimiento.

${ }^{30}$ Johann Michel se refiere a un "hegelianismo herido" (hegélianisme brisé) para caracterizar esta forma de relación con Hegel.
} 
y a muchas alianzas antitéticas de diferentes formas de pensar- llevó al filósofo a desarrollar la teoría del conflicto. A este nivel teórico, podemos decir que fue tanto detectivista (encontró conflictos) como constructivista (estableció algunos conflictos como medios para enriquecer su pensar ampliado). Por ello, el conflicto fue quizá su punto de partida. Es necesario decir, además, que se ha preocupado por darle tratamientos particulares a cada uno de los muchos conflictos que analizó. En el caso del conflicto entre el pensamiento arqueológico y el pensamiento teológico, por ejemplo, parece haber escogido uno de los lados -sus palabras revelan su preferencia por la ampliación de la hermenéutica-. De modo que, en este caso, no hay realmente una tercera posición. Más bien, hay dos posiciones diferentes, y Ricœur parece preferir una a la otra. Algo completamente distinto ocurre en el conflicto entre la explicación y la comprensión. Cuando Ricœur afirma la primacía de la comprensión sobre la explicación, pero sostiene la necesidad de la hermenéutica para hacer un largo rodeo en el reino de las ciencias humanas -explicar más es comprender mejor ${ }^{31}$ - realmente está produciendo una tercera y ampliada posición, la que conduce a una solución (realmente, una conciliación) de dicho conflicto.

Estos conflictos siguen siendo muy formales, casi esquemáticos. Sin embargo, en el mundo de la acción humana, los conflictos pueden ser más bien complejos, con múltiples núcleos y carentes de solución. Mediación, conciliación y dialéctica son todos procesos metodológicos a un nivel teórico -para los que deberíamos añadir el compromiso al nivel práctico-. Todos ellos apuntan hacia posibles soluciones. Con lo dicho hasta ahora, esperamos que quede claro que Paul Ricœur no soñó con una filosofía pacífica, que hubiera vencido todas sus tensiones. Así como tampoco conciliación significa para él que los conflictos hayan sido neutralizados, como si todas las posiciones fuesen equivalentes. La dialéctica entre el conflicto y la conciliación no debe ser entendida como un mecanismo formal, que anularía por yuxtaposición posiciones teóricas opuestas. Más bien, es la complejidad intrínseca a las diversas posiciones (con resultados completamente imprevisibles) la que permite las conciliaciones provisionales. Estas pueden iluminar algunos fenómenos -acción humana, interpretación, la naturaleza de la voluntad humana o del poder- en algún punto dado del propio desarrollo intelectual; una de las partes del conflicto puede conquistar a la otra y probar su validez;

31 “expliquer plus c'est comprendre mieux" (Ricœur, 1986, p. 22). 
o se podría probar que ambas son insuficientes. Pero siempre contribuirán a la ampliación de la perspectiva.

La mediación es el pasaje de uno al otro polo del conflicto; Ricœur la usa todo el tiempo - la imaginación es la mediación entre nosotros y la realidad, la ética logra la transición entre la filosofía de la acción y la ontología, la regla moral media el deseo inocente de la buena vida y la "solicitud crítica" $\mathrm{y}$, así-. La famosa voie longue, el gran rodeo, es el mejor ejemplo de este procedimiento. Es la operación de construir puentes, establecer conexiones, la que Paul Ricœur realiza constantemente-el hecho biográfico de que enseñó en Europa y Chicago, introduciendo la fenomenología a los estudiantes americanos y la filosofía analítica a los estudiantes europeos, es evidencia interesante y nos ayuda a comprender el que haya querido conectar distintas realidades-.

En cuanto a la conciliación, consiste en comprender el hecho de que los múltiples polos puedan cohabitar entre sí; se trata de comprender el fenómeno de la sobredeterminación. La conciliación es la real conditio sine qua non del pensar juntos en el sentido ricœuriano - es esto lo que de algún modo hemos querido sostener aquí-. Resumiendo, la conciliación es el y antes del $o \ldots o$. Se trata de una pluralidad sin totalidad y no del relativismo -todo es interpretación, como Nietzsche diría; simplemente, algunas interpretaciones son mejores que otras, y hay procedimientos metodológicos serios que están ahí para ayudarnos a distinguir precisamente eso-. De todos esos procedimientos, el dialéctico es el más abarcador. De hecho, toda la interacción entre los diferentes polos de dicha atracción es dialéctica -con las limitaciones mencionadas antes: incompletez, falta de síntesis, perpetua reformulación. Cuando se logra, se produce una nueva posición, un nuevo sentido. Es el eterno lazo entre atracciones y repulsiones, distanciamiento y apropiación, el que se alimenta por la lectura y lucha por la originalidad.

Si intentamos organizar todos estos procedimientos de un modo esquemático, encontraremos que hay un primer conflicto $\mathrm{y}$, luego, una primera tentativa de conciliación, que es responsable por la aparición del sentido. Este momento es, en cualquier filósofo, el desarrollo de una teoría. La llegada del segundo conflicto es equivalente a la crítica. La introducción del conflicto tiene la misma función que la crítica filosófica. Podemos comparar el instante en el que una conciliación tentativa es planteada con el momento en que una teoría nace, o un paradigma, en el sentido kuhniano, se impone. 
Una segunda aparición del conflicto sería equivalente al momento de crisis. Esta da paso a preguntas que la teoría precedente (o conciliación) no pueden responder. Entonces, la teoría precedente debe ser cuestionada y es así como la filosofía puede evolucionar. No queremos, de ningún modo, proponer que la metodología ricœuriana sería un modelo para entender el modo en que ocurren las evoluciones o cambios de paradigmas en la filosofía. Más bien, se trata aquí justamente de todo lo contrario: la perspectiva kuhniana podría ayudarnos a entender, mutatis mutandis, la dialéctica del conflicto y la conciliación, así como la caracterización del sentido, en esta rica y compleja filosofía.

No podríamos explicar aquí la génesis de la noción de la crítica filosófica ni desarrollar por completo todas sus implicaciones. En Kant, la noción de la crítica se deriva de la limitación de las facultades, a saber: la razón -lo que está aquí en juego es la limitación del conocimiento a priori al cuidado del área circunscrita de conceptos cuyos objetos son dados por la experiencia. Esta noción de crítica inmanente sufrirá numerosas metamorfosis en las obras de Hegel, Marx, Adorno y Honneth, especialmente cuando se aplica al análisis del mundo social y a la lucha por la emancipación. Dejaremos de lado, en este artículo, la tarea de explicar rigurosamente las implicancias de este desarrollo y nos concentraremos, más bien, en el doble aspecto que podría estar presente en la labor de crítica ${ }^{32}$.

En el Prefacio a la segunda edición de la Crítica de la razón pura, Kant afirma que la crítica es doble: primero, y especialmente, es un procedimiento negativo, cuando se utiliza para mostrarnos los límites de una facultad dada - en este caso, en la Crp, los límites de una razón especulativa-. Como sabemos, es una crítica interna, en tanto los límites son descubiertos desde dentro y lo que resulta es una restricción. No obstante, Kant señala también que desde el momento en que la crítica remueve un obstáculo -aquí, el ilegítimo uso de la razón especulativa- tiene, por tanto, un sentido positivo (Kant, Crp, B XXIV-B XXV). Este sentido positivo es posible gracias a la

\footnotetext{
${ }^{32}$ Doy gracias a Eileen Brennan por mostrarme el doble aspecto de la crítica kantiana, al brindarme el acceso a su tesis doctoral inédita, y por alentarme a encontrar un aspecto positivo en la crítica de Ricœur. La doble crítica kantiana (con sus aspectos negativos y positivos) y su influencia en Husserl y Heidegger es analizada en el primer capítulo "The Historical Origins of Phenomenological Destruktion", especialmente en la sección 1.3, "The methodological concept of Kritik" (Brennan, 1995).
} 
eliminación de lo excedente. Una vez que nos deshacemos de ello, cesa el estado problemático en el que se encontraba la razón y se puede, entonces, dar inicio a una filosofía más rigurosa. Una de las principales consecuencias, en la filosofía de Kant, es que luego pueden tener lugar las investigaciones de la razón práctica. La pregunta sería: ¿es la crítica, en sentido ricœuriano, también doble? ¿Tiene también esta un aspecto positivo?

Afirmaremos aquí que sí, pero, curiosamente, en un sentido diferente del que se manifiesta en Kant, pues estamos equiparando a la crítica con el conflicto. En cierto modo, el conflicto también hace patente los límites. Sin embargo, si hemos comprendido bien, lo que se señala en este caso son los límites del reduccionismo. Nosotros tampoco podemos explicar completamente el fenómeno de la conciencia fenomenológica, ni restarle la explicación con el psicoanálisis. No podríamos explicar la fe, ni la ética, con la crítica genealógica. Así pues, de alguna manera, lo que la crítica ricœuriana hace es mostrar los límites de la teoría -0 , por lo menos, los límites de algunas teorías- para develar las posibilidades de los fenómenos. La crítica positiva, en Ricœur, consiste en lo siguiente: mostrar la riqueza de la vida y tratar de captarla teóricamente. Esta es la razón por la que raramente usa la crítica destructiva. Su cortesía y su franqueza lo llevan a balancear siempre la deconstrucción con la re-construcción ${ }^{33}$. Finalmente, creemos que es una filosofía que nos persuade y está a la vez abierta a sus otros, sin importar quiénes sean.

Las palabras finales de este texto son para los lectores. ¿Habrá una forma ricœuriana de leer? ¿Cómo deberían leerse sus obras? Esto también plantea la pregunta acerca del estatus que debemos concederle a sus obras. Mencioné antes que nos encontramos aquí con obras que no tienen un único principio unificador; carecen de dicha unidad pero apuntan hacia múltiples direcciones en búsqueda de posibles unidades. Esto implica que el corpus ricœuriano es simultáneamente abierto y cerrado. Cerrado porque Ricœur murió en 2005 y, aunque escribió hasta el final de su vida (Ricœur, 2007), su prolífica producción ha cesado. Pero, por otro lado, la lectura y reinterpretación de su obra es todavía una labor en proceso, mucho más ahora que el Fonds Ricour abre sus puertas y subvenciona el acceso a los archivos en los que se halla material importante. Este material, compuesto de

\footnotetext{
${ }^{33}$ Ver, sobre este tema: Michel, 2005, p. 215.
} 
cursos, lecturas, conferencias y otros textos puede contribuir para tener una mejor comprensión de su desarrollo intelectual. Las vías en las que Ricœur puede influir en la filosofía de hoy están ya dispuestas para ser exploradas y reconstruidas.

Entonces, ¿cómo deberíamos leer sus trabajos? Del mismo modo en que él leyó el trabajo de otros filósofos - con respeto, pero no con devoción-. Es decir, que habremos de ser agradecidos con la posibilidad de aprender inmensamente de sus análisis, pero también habremos de poner a prueba las conciliaciones provisionales que planteó en su filosofía, al seguir sus guías teóricas y poner constantemente a la filosofía en marcha a través de un perpetuo acto de reinterpretación. Haciéndolo, estaremos homenajeando a Ricœur y, al mismo tiempo, desarrollaremos una mejor comprensión de nosotros y del mundo en que vivimos.

\section{Referencias}

Abel, O. (2006). "L’indépassable dissenssus". La Juste mémoire. Lectures autour de Paul Ricœur (pp. 19-48). Paris: Labor et Fides.

Badiou, A. (2003). Le sujet supposé chrétien de Paul Ricœur. À propos de La mémoire, l'histoire, l'oubli. Elucidation, 6(7), pp. 19-24.

Boltanski, L. \& Thévenot, L. (1991). De la justification. Les économies de la grandeur. Paris: Gallimard.

Brennan, E. (1995). The Concept and Practice of Destruktion in the Early Heidegger. Tesis doctoral. Faculté de Philosophie, Institut Catholique de Paris.

Carvalho, M.J. (2007). “O egoísmo lógico e a sua superação - um aspecto fundamental do projeto crítico de Kant". L. Ribeiro Dos Santos. (Ed.), Kant: Posteridade e Actualidade. Colóquio Internacional (pp. 229-256). Lisboa: Centro de Filosofia da Universidade de Lisboa.

Carvalho, M.J. (2003). Problemas de desconfinamento de perspectiva: pensar por si, o pensamento de outrem e alguns preconceitos sobre a filosofia actual e o passado da filosofía. Os longos caminhos do ser - Homenagem a Manuel Barbosa da Costa Freitas (pp. 117-138). Lisboa: Universidade Católica Editora.

Gadamer, H.G. (2007). Wahrheit und Methode. G. von Figal (Hrg.). Berlin: Akademie Verlag. 
Greisch, J. (1985). L’Âge herméneutique de la raison. Paris: Cerf.

Hegel, G.W.F. (1983). Phänomenologie des Geistes. Stuttgart: Reclam.

Henriques, F. (2006). A esperança escatológica e o conflito de interpretações. $A$ Filosofia de Paul Ricœur (pp. 109-114). Coimbra: Ariadne.

Jauss H.R. (1978). Pour une esthétique de la réception. Paris: Gallimard.

Kant, I. (1974). Beantwortung der Frage: Was ist Aufklärung? Berlinische Monatsschrift (Bd. 4), pp. 481-494.

Kant, I. (1906). Kritik der reinen Vernunft. P. Gedan, W. Kinkel, J.H. v. Kirchmann, F.M. Schiele, Th. Valentiner, K. Vorländer (Hrsg.). Leipzig: Verlag der Dürr'schen Buchhandlung.

Michel, J. (2005). Herméneutique et Déconstruction. Études Phénoménologiques, 41-42, pp. 325-342.

Pippin, R. (2008). Hegel's Practical Philosophy. Rational Agency as Ethical Life. Cambridge: Cambridge University Press.

Portocarrero, M.L. (1992). A Hermenêutica do Conflito em Paul Ricœur. Coimbra: Minerva.

Riceur, P. (2008). Amour et Justice. Paris: Points.

Riceeur, P. (2007). Vivant jusqu'à la mort. Paris: Seuil.

Riceeur, P. (2004). Parcours de la reconnaissance. Paris: Stock.

Ricceur, P. (2000). La Mémoire, l'histoire, l'oubli. Paris: Seuil.

Ricenur, P. (1995a). La Critique et la conviction. Entretien avec François Azouvi et Mar de Launay. Paris: Calmann-Lévy.

Riceur, P. (1995b). Le Juste. Paris: Esprit.

Ricceur, P. (1995c). Réflexion Faite. Paris: Esprit.

Riceur, P. (1994). Lectures 3. Aux frontières de la Philosophie. Paris: Seuil.

Riceur, P. (1991). "Pour une éthique du compromis", entrevista con J-M. Muller y F. Vaillant. (Disponible en: www.fondsricœur.fr).

Ricceur, P. (1990). Soi-même comme un autre. Paris: Seuil. 
Riceur, P. (1987). “Auto compréhension et histoire”. Conferencia originalmente publicada en español. II.D.45 Vansina Bibliography. (Disponible en francés en: www.fondsricœur.fr).

Ricceur, P. (1986). Du Texte à l'action. Paris: Seuil.

Riceur, P. (1985). Temps et récit, tome III: le temps raconté. Paris: Seuil.

Ricceur, P. (1969). Le Conflit des interprétations. Paris: Seuil.

Riceeur, P. (1965). De l'Interprétation. An essai sur Freud. Paris: Seuil.

Riceeur, P. (1960). Philosophie de la volonté tome 2. Finitude et Culpabilité 1, l'homme Faillible. Paris: Aubier-Montaigne.

Ricceur, P. (1950). Philosophie de la volonté, tome 1. Le volontaire et l'involontaire. Paris: Aubier-Montaigne.

Riceuv, P. (1948). Gabriel Marcel et Karl Jaspers. Philosophie du Mystère et Philosophie du Paradoxe. Paris: Temps Présent.

Ricenur, P. \& Lacoque, A. (1998). Penser la Bible. Paris: Seuil.

Riceur, P. \& Dufrenne, M. (1947). Karl Jaspers et la philosophie de l'existence. Paris: Seuil.

Scott-Baumann, A. (2009). Ricoeur and the Hermeneutics of Suspicion. London: Continuum.

Vincent, G. (2008). La Religion de Ricœur. Paris: l'Atelier/Ouvrières.

Wiercinski, A. (ed.). (2003). Between Suspicion and Sympathy: Paul Ricœur's unstable equilibrium. Toronto: The Hermeneutic Press. 